\title{
Differential effects of exposure to ambient vanilla and citrus aromas on mood, arousal and food choice
}

René A de Wijk $k^{*}$ and Suzet M Zijlstra²

\begin{abstract}
Background: Aromas have been associated with physiological, psychological affective and behavioral effects. We tested whether effects of low-level exposure to two ambient food-related aromas (citrus and vanilla) could be measured with small numbers of subjects, low-cost physiological sensors and semi-real life settings. Tests included physiological (heart rate, physical activity and response times), psychological (emotions and mood) and behavioral (food choice) measures in a semi-real life environment for 22 participants.

Results: Exposure to ambient citrus aroma increased physical activity $(P<0.05)$, shortened response times in young participants $(P<0.05)$, decreased negative emotions $(P<0.05)$, and affected food choice $(P<0.05)$. Exposure to ambient vanilla aroma increased projected introvert emotions $(P<0.05)$. All effects were small relative to estimated effect sizes.

Conclusions: The test battery used in this study demonstrated aroma-specific physiological, psychological and behavioral effects of aromas with similar appeal and intensities, and similar food-related origins. These effects could be measured in (semi-) real life environments for freely moving subjects using relatively inexpensive commercially available physiological sensors.
\end{abstract}

Keywords: Ambient aroma, Behavior, Citrus, Food choice, Psychology, Olfactory effects, Performance, Physiology, Vanilla

\section{Background}

Our world is filled with ambient aromas with varying degrees of intensity and appeal originating from food and non-food sources. Food aromas contribute to food flavor, which in turn is a key factor in food preferences. Non-food aromas are typically present in the form of perfumes and skin care products. These products are often purchased by consumers in the belief that the aromas will make them happier, more self-confident or more refreshed. These beliefs are encouraged and enhanced by clever marketing, which has resulted in a billion dollar fragrance industry. Some of these beliefs are supported by scientific evidence from studies demonstrating effects on human mental and physical performance [1-12] on human behaviors, such as helping

\footnotetext{
* Correspondence: rene.dewijk@wur.nl

${ }^{1}$ WUR Food and Biobased Research, Consumer Science \& Intelligent Systems, P.O. Box 17, Wageningen AA 6700, The Netherlands

Full list of author information is available at the end of the article
}

behavior $[13,14]$ or behavior in shops $[15,16]$, restaurants [17] and casinos [18] and effects on mood and emotions $[19,20]$. Other studies suggest a physiological basis for some of these effects, demonstrated by changes in physiological parameters, such as electroencephalogram (EEG) activity, heart rate, skin conductance, blood pressure or respiration rate [21-26] during specific aroma exposures. Unfortunately, physiological, behavioral and psychological measurements are rarely combined in the same study, which limits the insight into the underlying mechanisms of aroma effects. A compounding factor is that many aroma studies originate from the somewhat obscure field of aromatherapy which does not consistently uphold scientific rigor [27]. We set out to develop a battery of simple tests to assess the effects of low-level ambient aromas on subjects' physiology and behavior in a realistic environment, using relatively inexpensive commercially available physiological sensors where feasible. Once developed, this test battery could be used to

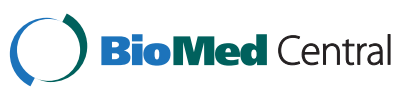


systematically screen aromas and gain insight into the mechanisms underlying the effects. This study describes our first steps towards this goal.

The present study combines a sound statistical design with physiological (physical activity, heart rate), psychological (mood and emotions) and behavioral (food choice and reaction times) tests to evaluate effects of two ambient aromas that are similar in appeal $[20,28,29]$ but with different stimulating properties [29]. The exposures took place in semi-real life (that is, non-laboratory) test situations and the physiological and behavioral measures focused on the ecologically relevant effects, namely activity monitoring as a real-life correlate of arousal and food choice behavior.

\section{Results}

\section{Data analysis}

All data were analyzed using the parametric General Linear Models (GLM) Repeated Measures, a statistical test that provides variance analysis for studies with repeated testing of the same dependent measures on the same participants. Because this study follows a withinparticipant design and the data were normally distributed, GLM Repeated Measures was the appropriate test to use. The between-subject category variables of age group and gender were included. Only significant effects of these variables are reported in the result section together with estimates of the effect size (95\% confidence intervals).

\section{Behavioral measurements \\ Food and drink choice}

Only exposure to ambient citrus aroma affected food choice as reflected by the significant aroma by food interaction (F $(2,44)=5.7, P=0.01)$. Post-hoc tests showed that exposure to citrus aroma reduced selection of cheese. A 95\% confidence interval for the aroma effect on cheese runs from 0.26 to 1.74 . Selection of cookies was unaffected by the aroma condition $(\mathrm{t}<1.44$, n.s.). Exposure to ambient vanilla aroma did not affect food choice $(\mathrm{F}(2,44)=1,6$, n.s.) (Figure 1$)$.

\section{Physiological affective measurements \\ Heart rate}

Heart rates averaged $76.5 \pm 6.5$ beats/minute during exposure to the odorless control, increased slightly to 77.1 \pm 6.4 beats/minute during exposure to citrus and decreased slightly to $74.4 \pm 6.4$ beats/minute during exposure to vanilla. A $95 \%$ confidence interval for the aroma effect on heart rate runs from 72.1 to 80.6. Inspection of the results indicated that this effect was not related to one specific period during the session. Posthoc tests demonstrated that exposure to ambient vanilla

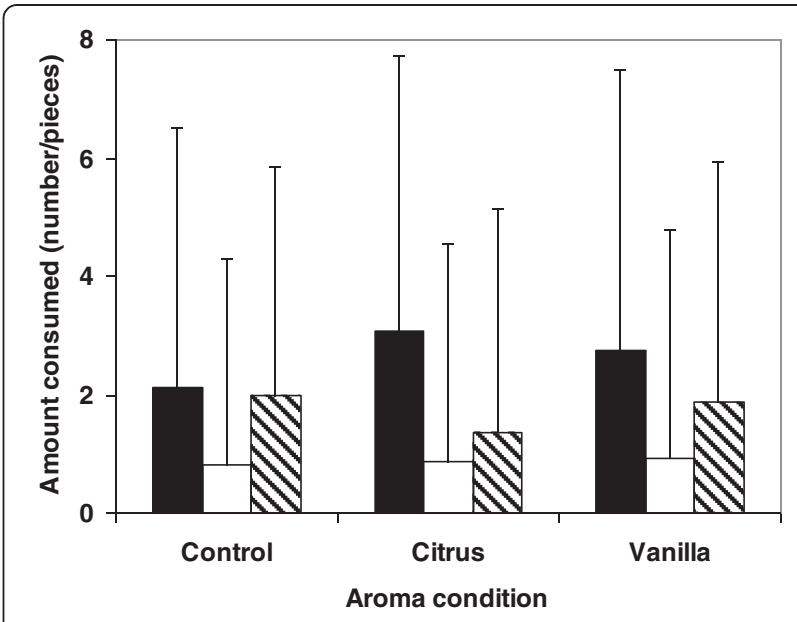

Figure 1 Effect of aroma on food choice. Number of portions of mandarin oranges (black bar), cookies (white bar), and cheese (hatched bar) consumed during exposure to ambient citrus and vanilla aromas and to the non-aroma control. Error bars are standard deviations.

aroma decreased heart rate significantly compared to exposure to ambient citrus aroma $(P<0.05)$.

\section{Energy expenditure}

Exposure to the two aromas did not significantly affect energy expenditure expressed in calories per minute. Expressed as Metabolic Equivalents of Tasks or METs (see Method section for explanation), activity levels were significantly higher during exposure to the citrus aroma $(1.23 \pm 0.38)$ compared to exposure to the vanilla aroma $(1.07 \pm 0.13)$ and to the odorless control $(1.09 \pm 0.16)$ (F $(2,40)=7.7, P=0.002$ ) (see Figure 2). A 95\% confidence interval for the aroma effect on MET runs from 1.02 to 1.25 . The aroma condition affected young participants more than middle-aged participants, as indicated

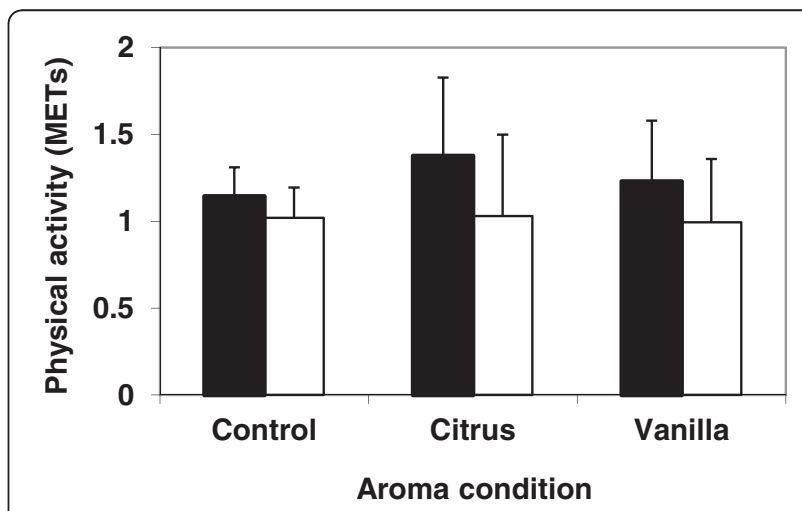

Figure 2 Averaged levels of physical activity of young (black bar) and middle-aged (white bar) participants during exposure to ambient citrus and vanilla aromas and to an odorless control. Error bars are standard deviations. 
by the significant interaction between aroma condition and age group $(\mathrm{F}(2,40)=5.2, P=0.02)$ (Figure 3$)$.

\section{Response time test}

Response times for incorrect responses were omitted from the analyses. Median correct response times for edible test words were significantly shorter than those for non-edible test words (466 \pm 77 vs. $488 \pm 102 \mathrm{msec}$, $F(1,21)=5.3, P=0.03)$. The effect of the aroma condition on response times for the young participants differed significantly from that of the middle-aged participants $(F(1,14)=5.3, P=0.03$ ) (Figure 2). Inspection of the young participant results demonstrated shorter response times in the citrus condition and longer response times in the vanilla condition.

\section{Psychological affective measurements Projected emotions}

Aroma conditions affected projected "introvert" emotions significantly $(\mathrm{F}(2,40)=3.0, P<0.05)$, with higher ratings for the vanilla condition $(3.80 \pm 1.15)$ than for the citrus $(3.51 \pm 0.96)$ and control conditions (3.29 \pm 0.84$)$. A $95 \%$ confidence interval on the effect on projected introvert emotions runs from 3.13 to 3.87 . No significant aroma effect was observed for any of the other 11 projected emotions.

\section{Mood test (PANAS)}

Scores for the positive emotions were not affected by the aroma condition, that is, there was no main effect of aroma condition or significant interactions between the aroma condition and exposure duration (PANAS tested at the beginning and end of the session). In the citrus condition, negative emotions became less intense during exposure indicated by a significant interaction between aroma condition and duration of test $(\mathrm{F}(2,40)=3.90$, $P=0.03$ ) (Table 1). A $95 \%$ confidence interval runs from 1.10 to 1.28 .

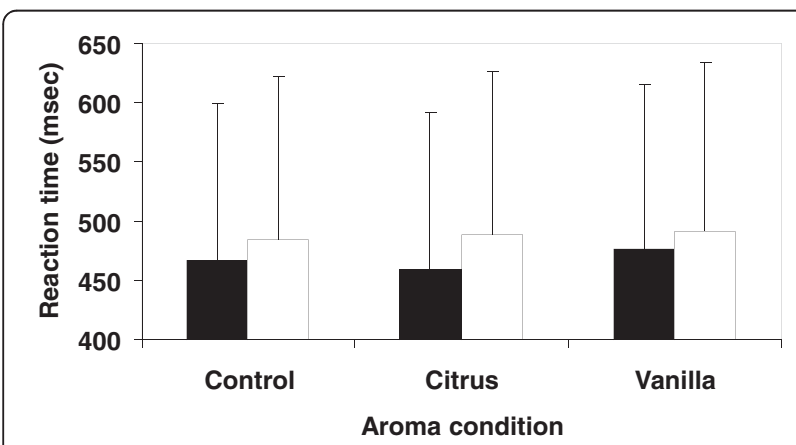

Figure 3 Response times for semantic decision test of young (black bar) and middle-aged (white bar) participants during exposure to ambient citrus and vanilla aromas and to an odorless control. Error bars are standard deviations.

\section{Interviews}

All participants described the test environment as "pleasant", "clean" and "a good place to work". Some thought the ventilation was "noisy", or felt it caused a "chilly breeze". Among the subjects, only one (first session) and two (second week) commented spontaneously on the ambient aroma in the room. In the third week, when the subjects were asked to speculate about the goal of the study, five subjects used the word 'aroma', but only two of them mentioned the influence of aroma on food choice. Results of the final ambient aroma questionnaire indicated that 11 of the subjects were unable to recognize any aromas, 8 only recognized the vanilla aroma, 2 only recognized the citrus aroma, and 1 was able to recognize both aromas.

The test results are summarized in Table 2.

\section{Discussion}

Exposures to ambient citrus and vanilla aromas showed differential behavioral, psychological and physiological effects. Exposure to citrus resulted in elevated mood, increased physical activity in young adults, and affected food choice. In contrast, exposure to vanilla only affected projected emotions. Some of the effects varied with the subject's age or with the degree of exposure to the aromas. Even though most of the effects on individual tests are small relative to the estimated effect size, the pattern of results is impressive because it demonstrates that two ambient aromas produce different physiological, psychological and behavioral effects despite their similarity in terms of appeal and intensity. Future tests will explore systematically the effects of other aromas and aroma concentrations to further optimize this test set. Future tests will also include longer exposure durations to verify whether the aroma effects persist or whether they disappear when the novelty effect of the aromas wear off. The outcome of these future studies will contribute to the identification of aromas that are optimized with regard to specific functionalities, such as improved mood, increased relaxation, increased physical

Table 1 Effect of aroma on mood

\begin{tabular}{llll}
\hline & Type of emotion & Positive & Negative \\
\hline Aroma condition & Exposure duration & Score \pm SD & Score \pm SD \\
\hline Citrus & Short & $3.89 \pm 0.54$ & $1.26 \pm 0.36$ \\
\hline Citrus & Long & $3.71 \pm 0.60$ & $1.12 \pm 0.18$ \\
\hline Control & Short & $3.77 \pm 0.60$ & $1.20 \pm 0.27$ \\
\hline Control & Long & $3.78 \pm 0.50$ & $1.19 \pm 0.26$ \\
\hline Vanilla & Short & $3.70 \pm 0.53$ & $1.21 \pm 0.27$ \\
\hline Vanilla & Long & $3.65 \pm 0.71$ & $1.19 \pm 0.26$ \\
\hline
\end{tabular}

Averaged PANAS mood scores ( \pm SD) of positive affect and negative affect emotions per aroma condition (range 1 to 5) measured after short and long exposure durations. 
Table 2 Summary of effects of aroma

\begin{tabular}{|c|c|c|c|c|c|}
\hline Type of test & $\begin{array}{l}\text { Type of } \\
\text { measurement }\end{array}$ & Effect measure & Effect & $\begin{array}{l}\text { Citrus } \\
\text { aroma }\end{array}$ & $\begin{array}{l}\text { Vanilla } \\
\text { aroma }\end{array}$ \\
\hline $\begin{array}{l}\text { Physiological affective } \\
\text { measurements }\end{array}$ & Heart rate & Heart rate & Stimulation/ relaxation & $\mathrm{x}$ & \\
\hline $\begin{array}{l}\text { Physiological affective } \\
\text { measurements }\end{array}$ & Physical activity & Energy expenditure, METs & Stimulation & $X^{*}$ & \\
\hline $\begin{array}{l}\text { Physiological affective } \\
\text { measurements }\end{array}$ & Response time test & Response time & Stimulation & $X^{*}$ & \\
\hline $\begin{array}{l}\text { Psychological affective } \\
\text { measurements }\end{array}$ & Mood test (PANAS) & $\begin{array}{l}\text { Positive and negative } \\
\text { emotions }\end{array}$ & $\begin{array}{l}\text { Priming and } \\
\text { congruency }\end{array}$ & $x$ & \\
\hline $\begin{array}{l}\text { Psychological affective } \\
\text { measurements }\end{array}$ & $\begin{array}{l}\text { Projective emotion } \\
\text { test }\end{array}$ & $\begin{array}{l}\text { Positive and negative } \\
\text { emotions }\end{array}$ & Mediation of emotions & & $x$ \\
\hline Behavioral measurements & Food choice & Cheese consumption & Satiety & $x$ & \\
\hline
\end{tabular}

* in young participants.

Significant results are indicated by " $\mathrm{X}$ ".

Summary of the effects of exposure to ambient citrus and vanilla aromas on the tests used in the present study.

activity or other healthy behaviors, including food choice and food intake.

The present study does not investigate possible causalities among the physiological, psychological and behavioral effects, but it has been argued by others that the physiological reactions probably have a psychological origin [27]. Certain aromas, for example, the pleasant ones, have in general positive effects on our mood, whereas others have negative effects. Different effects of mood trigger different physiological reactions. The specific psychological and physiological effects of aromas are not stable, but vary with age, gender, experience and culture. For example, the aroma of Limburger cheese is initially disliked but appreciated with increasing exposure, and the aroma of wintergreen is universally liked in the United States of America and universally disliked in Europe [27].

Even though the present study is exploratory and limited to only two aromas, the results have some interesting implications. The differences between vanilla and citrus are not self-evident, as the two most probable explanations, namely differences in appeal and in intensity can probably be excluded. Both aromas are pleasant, as indicated by other research [29] and the aromas were presented at barely detectable levels that were not consciously perceived by most subjects. In addition, both aromas belong to the same general category of food-related aromas. These results suggest, first, that effects of ambient aromas are specific and at least partly independent of intensity, appeal and category and, second, that conscious processing of aromas may not be a necessary requirement for their effect (also suggested by Wexler et al. [30]); and finally, that psychological and behavioral effects seem to be accompanied by physiological effects.

\section{Conclusions}

The test battery used in this study demonstrated aromaspecific physiological, psychological and behavioral effects of aromas with similar appeal and intensities, and similar food-related origins. These effects could be measured in (semi-) real life environments for freely moving subjects using relatively inexpensive commercially available physiological sensors.

\section{Methods \\ Participants}

Participants were recruited via the database of the Food \& Biobased Research organization. All participants had a normal sense of smell as determined by the European Test of Olfactory Capabilities (ETOC). Twenty-four non-allergic and non-vegetarian participants were selected based on gender, age and weight. Vegetarians were excluded because some of the tests referred to meat products. One participant was a smoker. All participants signed consent forms to participate in the study. To test systematic effects of age and gender, participants were divided into two age groups, namely "young" (32.0 yrs. $\pm 10.3 \mathrm{SD})$ and "middle-aged" (51.1 yrs. \pm 4.0 $\mathrm{SD})$. Within each age group, equal numbers of males and females were recruited. Twenty-two participants (13 females and 9 males) completed the study. The study protocol was approved by the Social Science Ethics Committee of Wageningen University.

\section{Test facilities}

The study was carried out in the so-called 'mood rooms' located at the research facilities of the Restaurant of the Future in Wageningen, The Netherlands. The mood rooms are four identical test rooms $\left(12 \mathrm{~m}^{2}\right.$ in size) which are sparsely decorated and furnished, and 
equipped with cameras mounted in the ceiling to monitor the activity of participants, and vaporizers and air conditioners to control ambient conditions. Ambient temperature was held at $21^{\circ} \mathrm{C}$. Three of the four rooms were used in this study, one for each aroma condition. One room was scented with the citrus aroma, one with the vanilla aroma and one room was kept/remained odorless. Participants were unaware of the presence of the vaporizers and aroma concentrations were kept at barely detectable levels. These levels had been determined in a pilot study in which groups of consumers were rotated through the rooms with different concentrations of the aromas in each room. Consumers were asked to indicate if they smelled an odor and, if they did, what kind of odor it was. With the results of this study we set the concentration levels of the ambient aromas. The selected concentrations were noticeable in the pilot study by most of the consumers, but only when their attention was drawn to the aromas.

\section{Ambient aromas}

Vaporizers (AllSens Geurbeleving, Oosterhout, The Netherlands) filled with natural aromatic citrus and vanilla oils (Voit Aroma Factory, Martinsried, Germany) were used to generate ambient aromas. Clean air generated by a programmable compressor was passed through the saturated headspace of the aroma vessel into the space occupied by the test participants in 2-sec pulses every 10 minutes. Together with the room ventilation this produced a relatively stable intensity during the session. A vaporizer filled with water was used as an odorless control.

\section{Behavioral measurements}

Actual food choice of congruent and non-congruent foods While participants were exposed to each of the ambient aroma conditions, they were presented with plates of small portions of foods and drinks. Every plate contained congruent, non-congruent, and neutral food and drink. The plates consisted of citrus-congruent (mandarin orange segments and orange juice), vanillacongruent (vanilla cookies and milk) or neutral in relation to either aroma (cubes of cheese and mineral water). The participants were led to believe that the food and drinks were presented only for their convenience and that they were free to sample from them during the session,except during the response time test. Consumption of food during exposure was measured by tallying food present at the beginning and end of the session. Similarly, the drinks were weighed at the beginning and end of the session.

\section{Physiological affective measurements}

Heart rate and physical activity These were monitored using the Polar S810 heart rate monitor and SenseWear BMS sensor system (BodyMedia Inc., Pittsburgh, PA. USA), respectively. The heart rate monitor monitors heart rate accurately [31] and consists of a receiver mounted in a wristwatch and a sensor placed with a belt around the chest. The Sensewear BMS sensor system is a commercially available sensor system designed to continuously monitor energy expenditure, activity and sleep efficiency accurately [32]. The total energy expenditure is the amount of energy expended in calories averaged across a session and includes the basal metabolic rate of the participants. To compensate for differences in session durations, energy expenditures were converted into energy expenditures per minute (total energy expenditure divided by session duration, expressed in $\mathrm{kcals} / \mathrm{min})$. Physical activity levels were expressed in Metabolic Equivalents of Tasks or METs. A MET-score of $1 \mathrm{MET}$ is the rate at which adults burn kcal at rest: this is approximately $1 \mathrm{kcal}$ per kilogram of body weight per hour (expressed as $1 \mathrm{kcal} / \mathrm{kg} / \mathrm{hr}$ ). For example, METs for dancing, hiking and running equal approximately $4.5,6$, and 7.5 .

Response time test A computerized semantic decision test was developed in which participants had to indicate as quickly as possible whether a word presented on the monitor placed in front of them referred to something edible (food) or inedible (part of the landscape or the interior of a house). At the beginning of each trial, the participant placed the index finger of his/her dominant hand on a marker located at equal distances from the left and right arrow buttons on the computer keyboard. As soon as the test word appeared on the monitor, the participants moved the finger to either the left or right arrow button to indicate whether the test word referred to something edible or inedible. To counterbalance for possible response biases, half of the participants had to press the right arrow button for an "edible" response and the left-button for an "inedible" response. For the other half of the participants the buttons for "edible" and "inedible" were reversed. A computerized timer recorded the time between the presented word and the press on the left or the right arrow button. A total of 200 test words were displayed, with a break of 30 seconds after the first 100 words. Per participant and aroma condition, the median response times for the set of edible and inedible responses were calculated to reduce the influence of outliers. 


\section{Psychological affective measurements}

Mood test The PANAS (Positive Affect and Negative Affect Schedule) questionnaire of Watson and Clark was used to assess each participant's mood status [33]. In this test participants rate their emotional status using a list of 20 emotions and a 5-point rating scale. The sub scores of the positive and negative mood scales were added and averaged [34].

Projective emotion test This test consisted of 24 photographs of male and female faces with comparable neutral expressions. Each face was judged by the participant using a set of 12 positive and negative descriptors. The positive descriptors were "kind", "enterprising", "cheerful", "open", "reliable" and "warm". The negative descriptors were "introvert", "arrogant", "tensed", "shy", "suspicious" and "discouraged". The set of 24 photographs was divided into 3 subsets of 8 photographs, each subset having a comparable mix of male and female faces. Each subset was used in one of the three aroma conditions. Subsets and aroma conditions were randomized across participants. Ratings for each descriptor were averaged per participant across subsets.

\section{Debriefing}

After the third and final session, participants were asked to speculate on the purpose of the study and on any ambient aromas they might have noticed during the sessions. The participants could indicate whether they smelled an ambient aroma in week 1, 2 and/or 3 as well as indicate the aroma. When participants did not remember the ambient aromas of the rooms they had been in several weeks ago, they were allowed to smell the available aroma samples. Based on these samples they could choose the aroma that they thought was present in the room on a certain day.

\section{Procedure}

Each participant participated in 3 separate 45 -minute session held at the same time on the same weekday during 3 consecutive weeks. Per session, a single participant was exposed to one of the ambient aroma conditions (citrus, vanilla and odorless control) during which he/she performed a number of tests. Participants were not told anything about the ambient aromas; nonetheless, the order of the aroma conditions was randomized across participants. At the start of each session, participants were equipped with the heart rate and activity sensors, and were guided into the experimental room where they received additional instructions for each test via a computer monitor. During the next two minutes a mood test was conducted, followed by the projective emotion test (five minutes), the response time test (eight minutes), the second mood test (two minutes) and, finally, an interview (three minutes) in which participants were questioned regarding their general impressions of the test procedures and the test environment. During each session participants had access to congruent, non-congruent and neutral food and drinks and participants were told that these were free for them to consume (food choice test). At the end of the third and final session participants were debriefed.

\section{Abbreviations}

ETOC: European test of olfactory capabilities; GLM: General linear models; METs: Metabolic equivalents of tasks; PANAS: Positive affect negative affect scale.

\section{Competing interests}

The authors declare that they have no competing interests.

\section{Authors' contributions}

RdW and SZ conceived the idea for the study, designed the study and carried out the statistical analysis. SZ conducted the study. RdW and SZ wrote the manuscript together. Both authors read and approved the final manuscript.

\section{Acknowledgements}

We acknowledge the contributions of Drs. Hans Schepers and Jozina Mojet in setting-up the research program, Hans Burgers of AllSens in setting up the aroma delivery systems, and Dr. Jon Prinz for developing the response speed test. We also acknowledge the contributions of Drs. Jozina Mojet and E.P. Köster in the development of the projective emotion test, and of Ms. Hester Anniek Buesseler with editing the manuscript.

\section{Author details}

${ }^{1}$ WUR Food and Biobased Research, Consumer Science \& Intelligent Systems, P.O. Box 17, Wageningen AA 6700, The Netherlands. ${ }^{2}$ Division of Human Nutrition, Wageningen University, Wageningen, EV 6700, The Netherlands.

Received: 14 August 2012 Accepted: 5 November 2012

Published: 1 December 2012

\section{References}

1. Baron $R$, Bronfen MA: Whiff of reality: empirical evidence concerning the effects of pleasant fragrances on work-related behavior. J Appl Soc Psychol 1994, 24:1179-1203.

2. Ludvigson H, Rottman T: Effects of ambient odors of lavender and cloves on cognition, memory, affect and mood. Chem Senses 1989, 14:525-536.

3. Diego M, Aaron-Jones N, Field T, Hernandez-Reif M, Schanberg S, Kuhn CM, Galamaga M, Mcadam V, Galamaga R: Aromatherapy positively affects mood, EEG patterns of alertness and math computations. Int J Neurosci 1998, 96:217-224.

4. Degel J, Koster EP: Odors: implicit memory and performance effects. Chem Senses 1999, 24:317-325.

5. Warm JS, Dember WN, Parasuraman R: Effects of olfactory stimulation on performance and stress in a visual sustained attention task. J Soc Cosmet Chem 1992, 42:199-210.

6. Sullivan TE, Warm JS, Schefft BK, Dember WN, O'Dell MW, Peterson SJ: Effects of olfactory stimulation on the vigilance performance of individuals with brain injury. J Clin Exp Neuropsychol 1998, 20:227-236.

7. Millot $J$, Brand $G$, Morgan N: Effects of odors on response time in humans. Neurosci Lett 2002, 322:79-82.

8. Yagyu T: Neurophysiological findings on the effects of fragrance: lavender and jasmine. Integr Psychiatry 1994, 10:62-67.

9. Moss M, Cook J, Wesnes K, Duckett P: Aromas of rosemary and lavender essential oils differentially affect cognition and mood in healthy adults. Int J Neurosci 2003, 113:15-38.

10. Sakamoto R, Minoura K, Usui A, Ishizuka Y, Kanba S: Effectiveness of aroma on work efficiency: lavender aroma during recesses prevents deterioration of work performance. Chem Senses 2005, 30:683-691. 
11. Baron $\mathrm{R}$, Kalsher M: Effects of a pleasant ambient fragrance on simulated driving performance, the sweet smell of ... safety. Environ Behav 1998 30:535-552.

12. Raudenbush B, Corley N, Eppich W: Enhancing athletic performance through the administration of peppermint odor. J Sport Exer Psychol 2000, 23:156-160.

13. Baron $R$ : The sweet smell of ... helping: effects of pleasant ambient fragrance on prosocial behavior in a shopping mall. Pers Soc Psychol 1997, 23:498-503.

14. Grimes M: Helping Behavior Commitments in the Presence of Odors: Vanilla, Lavender, and No Odor. Hypertext Paper: Georgia Southern University; 1999.

15. Knasko K: Ambient odor and shopping behavior. Chem Senses 1989, 14:719.

16. Lipman J: Scents that encourage buying couldn't smell sweeter to stores. Wall Street J 1990, :5

17. Guéguen N, Petr C: Odors and consumer behavior in a restaurant. Int J Hospital Manag 2006, 25:335-339.

18. Hirsch A: Effects of ambient odors on slot-machine usage in a Las Vegas casino. Psychol Marketing 1995, 12:585-594.

19. Lehrner J, Marwinski G, Lehr S, Johren P, Deecke L: Ambient odors of orange and lavender reduce anxiety and improve mood in a dental office. Physiol Behav 2005, 86:92-95.

20. Alaoui-Ismaïli O, Robin O, Rada H, Dittmar A, Vernet-Maury E: Basic emotions evoked by odorants: comparison between autonomic responses and self-evaluation. Physiol Behav 1997, 624:713-720.

21. Walter WG: Contingent negative variation: an electric sign of sensorimotor association and expectancy in the human brain. Nature 1964, 203:380-384

22. Torii S, Fukuda H, Kanemoto H, Miyanchi R, Hamauzu Y, Kawasaki M: Contingent negative variation (CNV) and the psychological effects of aroma. In Perfumery: the Psychology and Biology of Fragrance. Edited by Van Toller S, Dodd GH. New York: Springer; 1988:107-120.

23. Kuroda K, Inoue N, Ito Y, Kubota K, Sugimoto A, Kakuda T, Fushiki T: Sedative effects of the jasmine tea odor and R)-)-linalool, one of its major odor components, on autonomic nerve activity and mood states. Eu J Appl Physiol 2005, 952:107-114.

24. Duan X, Tashiro M, Wu D, Yambe T, Wang Q, Sasaki T, Kumagai K, Luo Y, Nitta I, Itoh M: Autonomic nervous function and localization of cerebral activity during lavender aromatic immersion. Technol Health Care 2007, 152:69-78.

25. Bensafi M, Rouby C, Farget V, Bertrand B, Vigouroux M, Holley A: Autonomic nervous system responses to aromas: the role of pleasantness and arousal. Chem Senses 2002, 278:703-709.

26. Dayawansa S, Umeno K, Takakura H, Hori E, Tabuchi E, Nagashimac Y, Oosu $H$, Yada $Y$, Suzuki T, Ono T, Nishijo H: Autonomic responses during inhalation of natural fragrance of cedrol in humans. Auton Neurosci Basic 2003, 1081:79-86.

27. Herz RS: Aromatherapy facts and fictions: a scientific analysis of olfactory effects on mood, physiology and behavior. Int J Neurosci 2009, 119:263-290.

28. Knasko SC: Ambient odor's effect on creativity, mood, and perceived health. Chem Senses 1992, 17:27-35.

29. Warrenburg S: Effects of fragrance on emotions: moods and physiology. Chem Senses 2005, 30:248-249.

30. Wexler BE, Warrenburg S, Schwartz GE, Janer LD: EEG and EMG responses to emotion-evoking stimuli processed without conscious awareness. Neuropsychologia 1992, 30:1065-1079.

31. Gamelin FX, Berthoin S, Bosquet L: Validity of the Polar S810 Heart Rate Monitor to measure R-R Intervals at rest. Med Sci Sports Exerc 2006, 38:887-893.

32. St-Onge $M$, Mignault D, Allison DB: Evaluation of a portable device to measure daily energy expenditure in free-living adults. Am J Clin Nutr 2007, 85:742-749.
33. Watson D, Clark LA, Tellegen A: Development and validation of brief measures of positive and negative affect: the PANAS Scales. J Person Soc Psychol 1988, 54:1063-1070.

34. Baeken C, Leyman L, De Raedt R, Vanderhasselt MA, D'haenen H: Left and right high frequency repetitive transcranial magnetic stimulation of the dorsolateral prefrontal cortex does not affect mood in female volunteers. Clin Neurophysiol 2008, 119:568-575.

doi:10.1186/2044-7248-1-24

Cite this article as: de Wijk and Zijlstra: Differential effects of exposure to ambient vanilla and citrus aromas on mood, arousal and food choice.

Flavour 2012 1:24.

\section{Submit your next manuscript to BioMed Central and take full advantage of:}

- Convenient online submission

- Thorough peer review

- No space constraints or color figure charges

- Immediate publication on acceptance

- Inclusion in PubMed, CAS, Scopus and Google Scholar

- Research which is freely available for redistribution 